\title{
CARREIRA E REMUNERAÇÃO DO MAGISTÉRIO NO MUNICÍPIO DE SÃO PAULO: ANÁLISE LEGISLATIVA EM PERSPECTIVA HISTÓRICA
}

\author{
Rubens BARBosa DE CAMARGO* \\ MARIA ANGÉliCA PEdRa Minhoto** \\ MÁRCIA APARECIDA JACOMINI ${ }^{* * *}$
}

\begin{abstract}
RESUMO: O trabalho estuda a carreira e a remuneração do magistério público municipal de São Paulo e analisa a forma de ingresso, jornada de trabalho, movimentação na carreira, dispersão salarial e composição da remuneração. As fontes primárias foram normas que tratam da carreira do magistério entre 1951 e 2010. Verificou-se que o concurso público foi o principal processo de contratação de docentes; houve alteração no número, tempo e composição da jornada de trabalho; para movimentação na carreira, preponderaram antiguidade, titulação e formação continuada; a dispersão do vencimento sofreu variações até 1994, tornando-se estável a partir de então, e a composição da remuneração apresentou acréscimos e variações em termos de adicionais, gratificações, abonos e prêmios.
\end{abstract}

Palavras-chave: Carreira. Valorização. Remuneração do magistério municipal de São Paulo.

\section{Teaching Career and Remuneration in SÃo Paulo:}

\section{LEGISLATIVE ANALYSIS IN A HISTORICAL PERSPECTIVE}

ABSTRACT: This paper examines the teaching career and remuneration of São Paulo's public educational system and analyzes the form of admission, workday, career progress, wage dispersion and salary composition. It is based on the rules for the teaching career between 1951 and 2010. It was found that the public tender was the main process of hiring teachers; there were changes on the number, composition and duration of the workday; when progress in the career is considered, seniority, qualification and

Faculdade de Educação da Universidade de São Paulo (USP). São Paulo (SP) - Brasil.

* Programa de Pós-Graduação em Educação da Universidade Federal de São Paulo (Unifesp). São Paulo (SP) - Brasil.

*** Programa de Pós-Graduação em Educação da Universidade Federal de São Paulo (Unifesp). São Paulo (SP) - Brasil.

Contato com os autores: <rubensbc@usp.br> 
continuing education predominated; wage dispersion underwent changes until 1994, becoming more stable thereafter; and there were variations on the remuneration composition in terms of additional bonuses, allowances, compensation and awards.

Key words: Career. Valorization. Municipal teacher remuneration in São Paulo.

Carrière et rémunération des enseignants a são paulo: ANALYSE LÉGISLATIVE DANS UNE PERSPECTIVE HISTORIQUE

RÉSUMÉ: Ce travail étudie la carrière et la rémunération des enseignants de la municipalité de São Paulo et analyse la condition d'accès, la journée de travail, la mobilité dans la carrière, la dispersion salariale et la composition de la rémunération. Les sources primaires ont été des normes qui abordent la carrière de l'enseignement entre 1951 et 2010. On a constaté que la concurrence publique a été la principale procédure pour embaucher des professeurs; il y a eu une modification dans le nombre, temps et composition de la journée de travail ; pour la mobilité dans la carrière, l'ancienneté, la qualification et la formation continue prédominaient pour faire avancer la carrière; la dispersion des salaires a fluctué jusqu'en 1994, en se rendant stables à partir de ce moment-là, et la composition de la rémunération a présenté des ajouts et variations sous forme des bonus supplémentaires, indemnités et récompenses.

Mots-clés: Carrière. Évaluation. Rémunération des enseignants à São Paulo.

\section{Introdução}

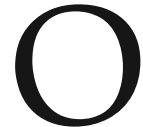

trabalho estuda a carreira e a remuneração do magistério público municipal da cidade de São Paulo e analisa as formas de ingresso, jornada de trabalho, movimentação na carreira, dispersão salarial e composição da remuneração docente, entre 1951 e 2010 . É um estudo documental e as fontes primárias foram normas que tratam da Rede Municipal de Ensino, do Estatuto do Funcionalismo e do Magistério municipal, dos planos de carreira e das modificações remuneratórias.

\section{Ingresso na carreira e vencimento do professor: identidade e valo- rização da profissão}

O ingresso na carreira docente por meio de concurso público está previsto, no Brasil, desde a Constituição Federal (CF) de 1934. Na cidade de São Paulo, a legislação estabeleceu o concurso público como forma de provimento aos cargos de professor, desde 1937, com o primeiro processo para contratação de educadores para os Parques Infantis, indicando, na própria origem da rede, um conjunto de características conformadoras do desempenho profissional, fomentando o profissionalismo e a 
identidade entre os educadores. De lá para cá, é possível verificar em todas as leis que instituíram e/ou modificaram os cargos do magistério público municipal a exigência de concurso público para o ingresso na carreira.

Desde a CF de 1934, o livre acesso dos cidadãos brasileiros ao exercício de cargos públicos tem sido garantido. A realização de concursos se coloca como antídoto às escolhas arbitrárias de indivíduos e como instrumento que fomenta o mérito para o desempenho de funções de interesse geral. Ao assentar-se na comprovação de diplomas e conhecimentos específicos para o exercício das funções e não em atributos como status social, relações familiares, apadrinhamentos pessoais, o concurso público tem como meta a efetivação de um recrutamento justo, oferecendo, ao menos no nível formal, igualdade de condições e oportunidades para os interessados no desempenho de funções públicas, em virtude do anonimato e impessoalidade dos certames, da divulgação prévia dos conteúdos das provas, de procedimentos objetivos de seleção, avaliação e classificação de candidatos, bem como do direito a recurso.

Além de professores concursados, a rede paulistana contou com a modalidade de provimento em "livre comissão", a partir da década de 1970, sob a responsabilidade da Secretaria Municipal de Educação (SME). Esse profissional, chamado de "professor comissionado", distinguia-se do cargo em comissão definido na CF/88 ou mesmo no Estatuto do Funcionalismo Municipal de São Paulo (Lei n. 8.989/79), já que se tratava de professores não concursados. $\mathrm{O}$ artigo 19 do Ato das Disposições Constitucionais Transitórias da CF/88 tornou estáveis os servidores que contavam com cinco anos ou mais de serviço público até a data de sua promulgação. Dessa forma, os "professores comissionados" que atendiam a tal preceito adquiriram estabilidade em seus cargos, passando a ser considerados "estáveis".

Em 1992, o Estatuto do Magistério (Lei n. 11.229/92) estabeleceu a contratação de professores por concurso público para substituir professores titulares, quando estes não estavam no exercício de sua função. Esses profissionais foram chamados de professores adjuntos e, apesar de concursados, não eram titulares de aulas ou classes. Essa forma de provimento estava vinculada ao compromisso de comprovar qualificação e garantir os mesmos direitos a todos os docentes, garantindo melhor qualidade de ensino aos alunos. Aos professores, tal premissa significou segurança por não perderem o emprego ao final ou início de cada ano letivo, caso não tivessem aulas ou classes disponíveis, como normalmente ocorre com docentes temporários. Com essa medida, o provimento em "livre comissão" foi extinto.

Na rede municipal de São Paulo, dada a existência legal de concursos desde 1937 e de sua realização periódica nas duas últimas décadas, a maior parte dos professores é efetiva. De acordo com a SME, em 2010, dos 56.872 profissionais da rede, 
$50.676(89 \%)$ eram efetivos. Em relação ao contrato temporário de professores para a substituição, a validade máxima é de um ano, podendo ser renovado por igual período (Lei n. 14.660/07).

A realização periódica de concursos públicos, como via quase que exclusiva de acesso ao magistério, aliada à definição de normas específicas que estruturam a carreira com exigências crescentes de certificação, à crescente organização sindical dos docentes e ao processo de diferenciação interna dos cargos docente, sem com isso submetê-los a carreiras e remunerações distintas, conferiram identidade e deram contornos à profissão na cidade de São Paulo. Por outro lado, a expansão do número de professores, ${ }^{1}$ em virtude da ampliação do atendimento escolar ao longo do tempo, sem a elevação proporcional de recursos financeiros para o aumento ou a manutenção da remuneração, levou a um processo de desvalorização social, econômica e salarial do docente, refletido no valor da hora-aula, e de alteração da imagem da profissão, nestes últimos anos.

Os dados presentes no Gráfico 1 mostram a evolução do valor da hora-aula trabalhada, referente ao vencimento base (VB), pago aos professores em início e final de carreira:

\section{Gráfico 1}

Valor da hora-aula em reais - início e final de carreira (1975-2010)

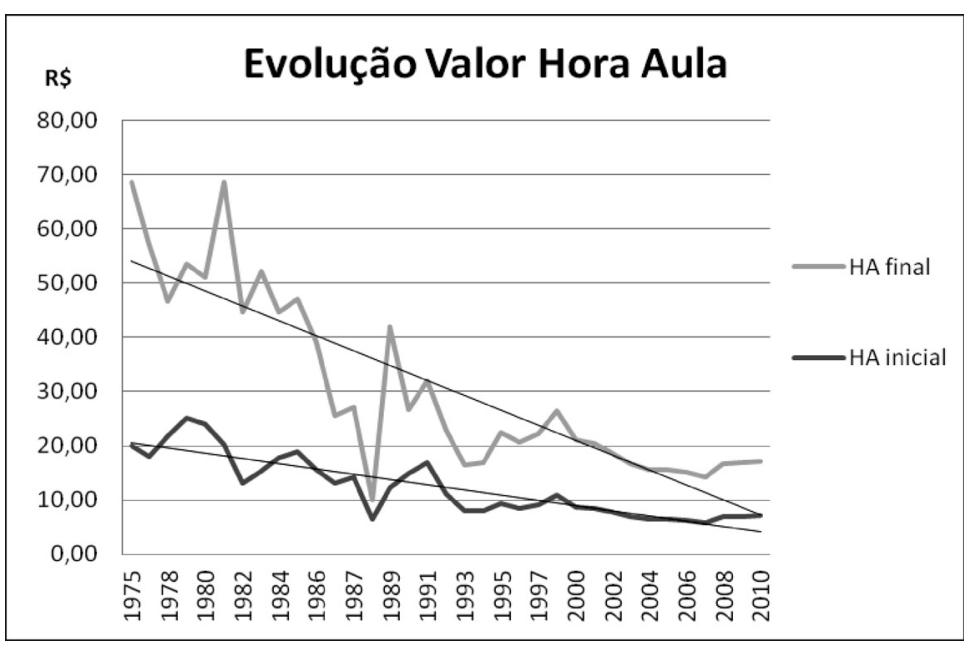

Fonte: elaboração dos autores, com base em leis e decretos municipais (1975-2010).

Nota: Valores corrigidos pelo Índice Geral de Preços - Disponibilidade Interna (IGP-DI/FGV), ${ }^{2}$ para 05/2010, data da última tabela de VB da série histórica. Para o cálculo do valor da hora-aula, foram consideradas cinco semanas no mês. 
É possível observar pela comparação entre as retas de tendência que o valor do vencimento no final de carreira sofreu perda mais acentuada que o de início de carreira: de $R \$ 68,57$ para $R \$ 17,12$, reduzido, portanto, à quarta parte do valor do início da série histórica. Para o início da carreira, o valor foi de $\mathrm{R} \$ 19,90$ para $\mathrm{R} \$ 7,09$, reduzido a pouco mais da terça parte do valor de início da série histórica. Além de indicar a redução no nível de dispersão ${ }^{3}$ do valor de retribuição da hora-aula, esse fato mostra a crescente desvalorização da carreira, na medida em que não proporcionou como contrapartida a elevação dos níveis salariais iniciais, o que poderia ter gerado maior atratividade para o ingresso na profissão. A série histórica de dispersão do VB pode ser observada no gráfico a seguir:

\section{Gráfico 2}

Relação entre vencimento em final e início de carreira (1975-2010)

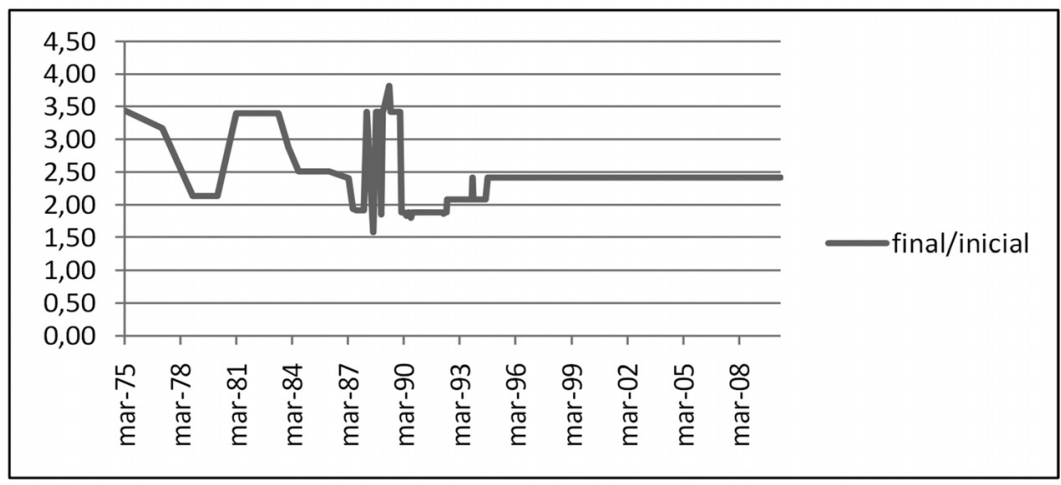

Fonte: elaboração dos autores, com base em leis e decretos municipais (1975-2010).

Nota-se que entre 1975 e 1994 ocorreram alterações importantes na relação entre o VB final e inicial, destacando-se o período de 1987 a 1990. O mês de julho de 1988, na gestão Jânio Quadros, é o que apresenta a menor diferença na relação entre os vencimentos, indicando dispersão equivalente a 57\%; menos de um ano depois, em maio de 1989, na gestão Luiza Erundina, nota-se a maior diferença da série histórica, quando o vencimento do docente em final de carreira passou a ser 3,8 vezes maior que o do iniciante. A flutuação entre os vencimentos em final e início de carreira só se estabilizou a partir de agosto de 1994, na gestão Paulo Maluf, quando os docentes no final de carreira passaram a receber em média 2,4 vezes mais que os vencimentos dos iniciantes, diferença que se mantém até hoje.

Atualmente, a dispersão salarial entre o vencimento inicial do professor formado em nível médio e o vencimento final do professor licenciado é de aproximadamente 141\%. Entretanto, a dispersão na mesma categoria é de aproximadamente 
$100 \%$, como se pode verificar na tabela de vencimentos ${ }^{4}$ mais recente, considerando-se que, para os docentes com formação em nível médio, a carreira vai do QPE11A ao QPE18E; para formação em nível superior, vai do QPE14A ao QPE21E.

\section{Tabela 1}

Vencimento do quadro do magistério municipal de São Paulo para a jornada básica do professor - $(20 \mathrm{~h} / \mathrm{a})$

\begin{tabular}{|c|c|c|c|c|c|}
\hline $\begin{array}{c}\text { REF/ } \\
\text { GRAUS }\end{array}$ & A & B & C & D & E \\
\hline QPE-11 & 709,10 & 755,20 & 804,29 & 856,63 & 912,27 \\
\hline QPE-12 & 755,20 & 804,29 & 856,63 & 912,27 & 971,55 \\
\hline QPE-13 & 804,29 & 856,63 & 912,27 & 971,55 & 1034,67 \\
\hline QPE-14 & 856,63 & 912,27 & 971,55 & 1034,67 & 1101,95 \\
\hline QPE-15 & 912,27 & 971,55 & 1034,67 & 1101,95 & 1173,57 \\
\hline QPE-16 & 971,55 & 1034,67 & 1101,95 & 1173,57 & 1249,94 \\
\hline QPE-17 & 1034,67 & 1101,95 & 1173,57 & 1249,94 & 1331,10 \\
\hline QPE-18 & 1101,95 & 1173,57 & 1249,94 & 1331,10 & 1417,66 \\
\hline QPE-19 & 1173,57 & 1249,94 & 1331,10 & 1417,66 & 1509,87 \\
\hline QPE-20 & 1249,94 & 1331,10 & 1417,66 & 1509,87 & 1608,02 \\
\hline QPE-21 & 1331,10 & 1417,66 & 1509,87 & 1608,02 & 1712,45 \\
\hline
\end{tabular}

Fonte: Decreto n. 51.526, de 28/12/2010

Pode-se notar, portanto, que o enquadramento por categoria configura-se como incentivo à titulação em licenciatura, já que sem isso o professor não chega à última referência da carreira. Vale lembrar que, diversamente de outras redes de ensino em que a titulação em nível de pós-graduação é considerada para enquadramento (GATTI; BARRETO, 2009), na rede municipal de São Paulo essa titulação foi e ainda é contabilizada de acordo com pontuação específica para fins de evolução funcional.

É preciso ponderar que uma dispersão salarial elevada pode tender a um baixo valor de vencimento inicial, o que em tese dificulta a contratação de profissionais experientes e qualificados. Uma dispersão reduzida pode significar uma carreira pouco estimulante, dado que a movimentação não produz impactos pecuniários significativos para os docentes. Há estudos que, considerando esses dois aspectos, defendem uma dispersão salarial em torno de 100\% (DUTRA JR. et al, 2000).

Entretanto, a tendência de desvalorização histórica dos vencimentos, verificada por mais de três décadas (Gráfico 1), mostra que os profissionais têm vivido tempos difíceis, sofrendo redução significativa em seu padrão de vida, aliada à precarização 
e à intensificação de seu trabalho (OLIVEIRA, 2004). Esses fatores geram expectativa negativa sobre a profissão, na medida em que aumentam as responsabilidades e as cobranças, ao mesmo tempo em que cai o valor da retribuição pelo desempenho do trabalho. Tal situação tem levado alguns docentes a buscar melhores carreiras e salários e colocado limites para o recrutamento de novos e qualificados quadros (GATTI et al., 2009). No caso da rede municipal de São Paulo, é bem comum o professor ampliar a jornada ou acumular cargo na mesma ou em outra rede de ensino.

Nota-se também (Gráfico 1) que o período de maior arrocho salarial ocorreu no ano de 1988, quando o prefeito era Jânio Quadros. Camargo (1997) e Matos (2010) mostram que a pasta da educação na época caracterizou-se pelo centralismo, assistencialismo e autoritarismo. Em decorrência, os professores, juntamente com outros funcionários públicos, entraram em greve, em abril de 1987. De acordo com Matos (op. cit.), o movimento foi violentamente reprimido e acabou com a demissão de quase 2 mil professores comissionados e com a abertura de processos administrativos contra várias lideranças do movimento. Posteriormente, na gestão de Erundina, esses professores foram anistiados (CAMARGO, 1997).

Nota-se ainda (Gráfico 1) que os valores de vencimentos dos professores tiveram uma breve recuperação na gestão de Erundina, mas logo voltaram a sofrer perdas importantes. A tendência de desvalorização salarial só se interrompeu recentemente e, a partir de 2008, se inverteu de forma bem atenuada. De acordo com Tedesco e Fanfani (2004, p. 71),

La masificación de los puestos de maestro, la elevación de los niveles de escolaridad media de la población, el deterioro del salario y las condiciones de trabajo y otros fenómenos conexos (pérdida de prestigio relativo del oficio, cambios em el origen social relativo de los maestros, etc.) constituyen las bases materiales sobre la que se va estructurando una representación de la docencia como un trabajo. La sindicalización del magisterio contribuirá a imponer una imagen social del maestro como trabajador que es asumido por porciones significativas de docentes.

Os autores argumentam que a imagem de trabalhador assalariado e militante é um dos três traços que têm estruturado a representação social da docência na modernidade - outros traços são os de professor como vocação-apostolado, presente mais intensamente no momento de fundação do ofício, e de professor como um profissional. Afirmam ainda que a luta por uma definição dominante desse ofício supõe combinações variáveis entre esses elementos e que "solo una visión de largo plazo permite apreciar el sentido de las diversas imágenes con que se piensa el magisterio de hoy" (p. 69).

Apesar da histórica desvalorização salarial, os traços de profissionalidade e de organização sindical da categoria podem ajudar a explicar a resistência do magistério em incorporar algumas das prescrições típicas das políticas ditas de profissionalização, 
desencadeadas com as reformas educacionais dos anos de 1990. Como exposto, praticamente inexistem professores com contratos "flexíveis" de trabalho (temporários ou precários) e, como se verá mais adiante, a remuneração não esteve, até o momento, atrelada a processos de avaliação de desempenho aferidos pela "qualidade do produto", ou seja, por exames estandardizados aplicados aos alunos.

\section{Desvalorização salarial e aumento da jornada de trabalho docente}

A jornada de trabalho do professor da rede municipal de São Paulo teve variação importante nos últimos trinta anos. Tomando como referência a criação do Departamento Municipal de Ensino, em 1967, até 2010, pode-se dizer que houve uma tendência de aumento das horas da jornada de trabalho e, principalmente, elevação no número de jornadas, conforme mostra o Quadro 1.

No período de 1967 a 1992, havia uma jornada parcial que variou de 20h a 27h e uma jornada integral de 40h que vigorou, no caso dos professores, por curto período de tempo (1975-1978), quando passou a ser exercida somente pelos chamados Especialistas em Educação (diretor, orientador e inspetor).

Até 1992, a jornada dos professores era composta por horas de regência de aula ou classe (horas-aula) e horas-atividade, o Estatuto do Magistério mudou essa concepção ao introduzir a Jornada de Tempo Integral (JTI), com duração de 30h, das quais um terço era destinado a atividades extraclasse com o objetivo de garantir horário de trabalho coletivo e atividade de formação continuada. Ao ingressar na carreira, os professores titulares e adjuntos faziam jus à Jornada de Tempo Parcial (JTP) de 20h. No entanto, quando em regência, podiam solicitar ingresso na JTI.

O professor em JTI trabalhava $20 \mathrm{~h}$ em regência e $10 \mathrm{~h}$ em atividades extraclasse, sendo $8 \mathrm{~h}$ destinadas ao trabalho coletivo na escola e $2 \mathrm{~h}$ a atividades individuais em local de livre escolha. Em relação à JTP, manteve-se 10\% de horas-atividade (2h).

A Lei n. 11.434/93 que sucedeu o Estatuto não modificou a concepção da JTI, mas fez modificações na nomenclatura e no número de jornadas, definiu as jornadas em horas-aula ${ }^{5}$ e criou jornadas especiais de trabalho. A JTP foi transformada em Jornada Básica do Professor (JB), correspondendo a 18 horas-aula e 2 horas-atividade semanais; foi criada a Jornada Especial Ampliada (JEA), com 25 horas-aula e 5 horas-atividade semanais, e a JTI foi transformada em Jornada Especial Integral (JEI), com 25 horas-aula e 15 horas-atividade semanais. Além dessas jornadas, foram instituídas a Jornada Especial de Hora Aula Excedente (JEX) e a Jornada Especial de Hora Trabalho Excedente (TEX), complementares à JB e à JEA. Na primeira, o professor ministrava aulas regulares livres ou em substituição ou aulas de reposição, 
além das correspondentes a sua jornada, e, na segunda, trabalhava na realização de projetos pedagógicos.

\section{Quadro 1}

Duração e composição da jornada de trabalho

\begin{tabular}{|c|c|c|c|}
\hline Jornada & Hora-atividade & Prefeito & Legislação \\
\hline $20 \mathrm{~h}$ & - & Faria Lima & Lei n. 7.037/67 \\
\hline $\begin{array}{l}27 \mathrm{~h} \\
40 \mathrm{~h}\end{array}$ & $20 \%$ & M. Colassuono & Lei n. 8.209/75 \\
\hline $24 \mathrm{~h}$ & $4 \mathrm{~h}$ & O. Setubal & Lei n. 8.694/78 \\
\hline $20 \mathrm{~h}$ & $10 \%$ & F. Altino Lima & Lei n. 9.662/83 \\
\hline $\begin{array}{l}\text { 30h (JTI) } \\
20 \mathrm{~h}(\mathrm{JTP})\end{array}$ & $\begin{array}{c}1 / 3-\text { JTI } \\
10 \%-J T P\end{array}$ & L. Erundina & Lei n. 11.229/92 \\
\hline $\begin{array}{c}\text { 40h/a (JEI) } \\
\text { 30h/a (JEA) } \\
\text { 20h/a (JB) } \\
\text { JEX e TEX - até } \\
\text { limite de } 232 \mathrm{~h} / \mathrm{a} \\
\text { mensais }\end{array}$ & $\begin{array}{c}15 \mathrm{~h} / \mathrm{a}-\mathrm{JEI} \\
5 \mathrm{~h} / \mathrm{a}-\mathrm{JEA} \\
2 \mathrm{~h} / \mathrm{a}-\mathrm{JB}\end{array}$ & P. Maluf & Lei n. 11.434/93 \\
\hline $\begin{array}{c}\text { 30h }(\mathrm{J} 30) \\
\text { 30h/a (JBD) } \\
\text { 40h/a (JEIF) } \\
\text { JEX e TEX - até } \\
\text { limite de 170h/a } \\
\text { mensais }\end{array}$ & $\begin{array}{c}5 \mathrm{~h}-\mathrm{J} 30 \\
\text { 5h/a - JBD } \\
\text { 15h/a - JEIF }\end{array}$ & G. Kassab & Lei n. 14.660/07 \\
\hline
\end{tabular}

Fonte: elaboração dos autores, com base em leis e decretos municipais (1967-2010).

A Lei n. 14.660/07 estabeleceu duas jornadas de trabalho aos professores: a Jornada Básica de 30h (J30), com 25h de regência e 5h de atividades, para o cargo de Professor de Desenvolvimento Infantil (PDI), criado pela Lei n. 13.695/03, exercido nos Centros de Educação Infantil (CEI), antigas creches; e a Jornada Básica do Docente (JBD), correspondendo a 30 horas-aula de trabalho semanal, com 25 horas-aula em classe e 5 horas-atividade, destinada a cargos de Professores de EI (pré-escola) e EF-I e Professor de EF-II e EM. Pela Lei, ao ingressar na carreira, o professor faz jus a uma dessas jornadas, de acordo com o cargo. Se estiver em regência ${ }^{6}$ pode solicitar anualmente o ingresso nas seguintes jornadas especiais: Jornada Especial Integral de 
Formação (Jeif), antiga JEI, composta por 25 horas-aula semanais e 15 horas-atividade; Jornada Especial de Trabalho Excedente (TEX) e Jornada Especial de Horas Aula Excedentes (JEX), cujo número de horas-aula pode chegar a 170 no mês.

Nas jornadas de 30h de trabalho (JTI de 1992) ou 40 horas-aula (JEI de 1993) com um terço da jornada destinada a atividades extraclasse, estava implícita a ideia de uma jornada compatível com as exigências e especificidades do trabalho pedagógico. Os professores que por elas optassem não poderiam complementá-las com trabalho ou aulas excedentes na rede municipal, condição modificada em 2007, ao se permitir TEX ou JEX ao docente em Jeif.

Em relação à composição das jornadas, observa-se que apenas uma garante um terço para atividades extraclasse (cf. Parecer CNE/CEB n. 9/2009 e Lei n. 11.738/08). Nota-se também a distinção entre os regimes de trabalho de professores nos CEI e nas escolas de EI, EF e EM. No caso dos CEI, a jornada de trabalho docente é computada em horas e $25 \mathrm{~h}$ das $30 \mathrm{~h}$ são destinadas às atividades com as crianças.

Outro aspecto a destacar é o aumento do número de jornadas, a partir de 1993 (Maluf), e o fato de que a jornada à qual o professor está vinculado no ingresso (JBD) não atender à composição de um terço para atividade extraclasse. Dessa forma, apesar dos avanços conquistados, ainda não se tem a perspectiva de uma jornada em tempo integral em uma única escola, com dedicação exclusiva, para o conjunto dos professores.

A combinação do aumento de horas nas jornadas e do número de jornadas possibilitou acúmulo de cargo de até 70h semanais de trabalho, conforme previsto na Lei n. 14.660/07. Esse movimento pode ser compreendido no marco da crescente desvalorização salarial dos docentes da educação básica, que levou de forma compensatória ao aumento de jornadas de trabalho (MONLEVADE, 2000). Contudo, destaca-se a diferença entre acumular duas jornadas de $20 \mathrm{~h}$ e acumular duas jornadas que somam 70h, como tem ocorrido na rede municipal de São Paulo.

A intensificação do trabalho docente, ocorrida na segunda metade do século $X X$, caminhou pari passu com a ampliação do atendimento educacional e às consequentes mudanças na dinâmica escolar e na forma de seu trabalho (FANFANI, 2007; OLIVEIRA, 2006). Nesse contexto, embora responsável por uma atividade cada vez mais complexa, o salário e o prestígio social do professor diminuíram significativamente desde os anos de 1950, produzindo condições que não coadunam com a especificidade e as exigências de uma atuação qualificada.

Dada essa condição, a discussão sobre a jornada de trabalho na rede municipal de São Paulo encerra certa complexidade, porque cerca de um terço dos professores tem acúmulo de cargos na própria rede ou em outras redes públicas de ensino ${ }^{7}$ e o estabelecimento de uma jornada em tempo integral com dedicação 
exclusiva demanda, do ponto de vista salarial, propostas capazes de atrair e manter professores que hoje acumulam remunerações por terem mais de um cargo.

Se, como visto, a segunda metade do século XX caracterizou-se pela ampliação da jornada de trabalho, na medida em que ocorria uma intensa desvalorização salarial, o início do século XXI, pelo menos no que diz respeito à legislação, parece apontar para a necessidade de aumento de salários e diminuição da jornada de trabalho rumo à jornada de tempo integral com dedicação exclusiva, condição necessária à realização de um bom trabalho pedagógico, a despeito de a legislação municipal estar em contradição com esse propósito.

\section{Movimentação na carreira e isonomia salarial}

Monlevade (2000, p. 51) afirma que, na segunda metade do século XX, especialmente durante o regime de exceção, "além do mecanismo individual de multiplicação de jornada e emprego", os professores procuraram relativizar as perdas salariais por meio da "'progressão funcional' via avanços estatutários, que se garantiam principalmente por tempo de serviço e titulação". De certa forma, a movimentação na carreira do magistério público até o final do século XX esteve ancorada na progressão por tempo e títulos.

A movimentação na carreira pode ser analisada com base no vencimento inicial, nas formas de progressão e na dispersão do vencimento. A progressão na carreira dos professores municipais, nos últimos 50 anos, tem sido baseada, principalmente, em tempo de serviço e títulos, conforme pode ser observado no Quadro 2.

O tempo contribui para a permanência do professor na rede, na medida em que vislumbra a possibilidade de melhores vencimentos. Os títulos incentivam a formação inicial em nível superior, bem como a formação continuada, além de serem critérios objetivos e garantirem a isonomia salarial.

De acordo com a Tabela 2, nota-se que o Estatuto (1992) foi um marco na organização da evolução funcional em 12 referências, mantendo os cinco graus existentes desde 1974. As leis subsequentes fizeram mudanças, mas mantiveram a mesma estrutura de 1992: evolução funcional (vertical) por tempo, por título ou pela combinação de ambos e promoção (horizontal) por antiguidade e merecimento, que consiste na avaliação do professor pela chefia imediata.

Os cargos foram reclassificados em Professor Nível I e II, professores adjuntos e titulares, respectivamente, e divididos em três categorias de acordo com a formação: 1, para nível médio; 2, para licenciatura curta e 3, para licenciatura plena. As referências inicial ${ }^{8}$ e final foram definidas de acordo com o Nível e a Categoria e, independente do enquadramento, o docente teria direito à evolução funcional por 
tempo, por títulos e por tempo e títulos combinados. Para requerer a primeira evolução, deveria ter no mínimo dois anos de efetivo exercício e as evoluções subsequentes deveriam observar o interstício de um ano na referência.

\section{Quadro 2}

Critérios de movimentação na carreira (1951-2007)

\begin{tabular}{|c|c|c|}
\hline Critérios & Prefeito & Legislação \\
\hline $\begin{array}{l}\text { Merecimento, tempo de serviço, tempo no cargo, } \\
\text { idade e encargos familiares }\end{array}$ & Arruda Pereira & Lei n. 4.128/51 \\
\hline Curso de aperfeiçoamento & Faria Lima & Lei n. $7.037 / 67$ \\
\hline Institui três padrões com interstício de dois anos & $\begin{array}{l}\text { Figueiredo } \\
\text { Ferraz }\end{array}$ & Lei n. 7.693/72 \\
\hline $\begin{array}{l}\text { Institui cinco graus: promoção por antiguidade } \\
\text { (julho) e merecimento (dezembro) - interstício de três } \\
\text { anos }\end{array}$ & M. Colassuomo & Lei n. 8.183/74 \\
\hline Muda para nove referências e cinco graus & O. Setúbal & Lei n. 8.209/75 \\
\hline Reduz para cinco referências & O. Setúbal & Lei n. 8.807/78 \\
\hline $\begin{array}{l}\text { Institui evolução funcional: primeira evolução em três } \\
\text { anos e demais com um ano + pontuação }\end{array}$ & M. Covas & Lei n. 9.874/85 \\
\hline $\begin{array}{l}\text { Institui categorias } 1,2 \text { e } 3 \text {; referências de } 1 \text { a } 12 \\
\text { (vertical) e graus de A a E (horizontal). Movimentação } \\
\text { por tempo, título e combinação de ambos - dois anos } \\
\text { para a primeira evolução, interstício de um ano }\end{array}$ & L. Erundina & Lei n. 11.229/92 \\
\hline Muda para QPE (11-21) & P. Maluf & Lei n. 11.434/93 \\
\hline $\begin{array}{l}\text { Categorias } 1 \text { (QPE } 11 \text { A a 18E) e } 3 \text { (QPE 14A a 21E) } \\
\text { Institui avaliação de desempenho: Certificação de } \\
\text { Valoração Profissional }\end{array}$ & G. Kassab & Lei n. 14.660/07 \\
\hline
\end{tabular}

Fonte: elaboração dos autores, com base em leis e decretos municipais (1951-2007).

A Lei n. 11.434/93 modificou a denominação das referências para Quadro dos Profissionais da Educação (QPE) e delimitou o topo da carreira para professores ao QPE21 e para especialistas ao QPE22, estabelecendo diferença entre vencimentos, o que não existia no Estatuto.

Em 2007, os professores portadores de diploma de ensino médio na modalidade Normal foram enquadrados na Categoria 1 e de diploma de ensino superior na Categoria 3. O enquadramento na Categoria 3 pode ser solicitado em qualquer momento da carreira, sendo necessário apresentar diploma em licenciatura plena. 
Nesse enquadramento consideram-se os graus e referências conseguidos por tempo, títulos ou a combinação de ambos, ao longo da trajetória profissional, e a diferença salarial entre as categorias é de $21 \%$.

\section{Tabela 2}

Evolução por tempo - Estatuto de 1992

\begin{tabular}{|c|c|c|c|c|c|c|}
\hline \multirow{2}{*}{} & \multicolumn{2}{|c|}{ Categoria 1 } & \multicolumn{2}{c|}{ Categoria 2 } & \multicolumn{2}{c|}{ Categoria 3 } \\
\cline { 2 - 7 } & \multicolumn{2}{|c|}{ Nível Médio } & \multicolumn{2}{c|}{ Licenciatura Curta } & \multicolumn{2}{c|}{ Licenciatura Plena } \\
\cline { 2 - 7 } & Titular & Adjunto & Titular & Adjunto & Titular & Adjunto \\
\hline EM-01 & & 0 & & & & \\
\hline EM-02 & 0 & 2 & & & & \\
\hline EM-03 & 2 & 5 & & 0 & & \\
\hline EM-04 & 5 & 8 & 0 & 2 & & 0 \\
\hline EM-05 & 8 & 12 & 2 & 5 & 0 & 2 \\
\hline EM-06 & 12 & 16 & 5 & 8 & 2 & 5 \\
\hline EM-07 & 16 & 20 & 8 & 12 & 5 & 8 \\
\hline EM-08 & 20 & & 12 & 16 & 8 & 12 \\
\hline EM-09 & 22 & & 16 & 20 & 12 & 16 \\
\hline EM-10 & & & 20 & & 16 & 20 \\
\hline EM-11 & & & 22 & & 20 & \\
\hline EM-12 & & & & & 22 & \\
\hline
\end{tabular}

Fonte: Anexo VI da Lei n. 11.229/92.

É importante destacar que, desde o Estatuto de 1992, o professor pode chegar à última referência da carreira após 22 anos de trabalho e antes disso, se realizar atividades de formação continuada que se convertem em títulos e permitem evolução funcional mais rápida. Os títulos também servem para que, em período igual, se chegue ao último grau, completando, assim, a carreira em termos de vencimento.

Essa concepção de carreira que, de acordo com Morduchowicz (2003), estava presente em diferentes países da América Latina até o final do século XX, vem sofrendo duras críticas de setores que defendem o fim da isonomia salarial e a introdução do pagamento por mérito, vinculado a avaliações de desempenho individual, independentemente das condições institucionais e da especificidade do trabalho educacional (ABREU; BALZANO, 2001; VEGAS, UMANSKY, 2005).

No caso brasileiro, entende-se que esta discussão ocorre no contexto da legislação federal sobre a valorização do magistério, desde a $\mathrm{CF} / 88$, e principalmente 
da reforma do Estado consubstanciada na Emenda Constitucional n. 19/1998. Desse modo, embora a Lei de 2007 não tenha alterado a forma de movimentação na carreira, ela introduz a avaliação de desempenho baseada na "Certificação de Valoração Profissional" que poderá, dependendo de sua regulamentação, fazer modificações importantes nas formas de movimentação funcional. Se regulamentada com base num sistema de avaliação que vincula a remuneração docente ao desempenho dos alunos, haverá mudança na concepção de carreira em relação ao Estatuto e leis anteriores.

Até 2010, a evolução funcional tem sido baseada em critérios objetivos de tempo e títulos. Embora a promoção comporte pontuação por mérito, não se trata de avaliações vinculadas ao desempenho dos alunos ou formas de avaliação em que uma parte dos professores é agraciada com melhores salários, pelo desempenho em avaliações individuais e desvinculadas do contexto em que são produzidos o trabalho e a atividade educativa. Ainda é uma carreira que reflete a concepção de que a docência é um trabalho eminentemente coletivo, cujos resultados dependem de muitos fatores e costumam se apresentar no longo prazo. Nas últimas décadas, alguns estudos têm mostrado a dificuldade de se estabelecer avaliações capazes de captar, de forma justa, os resultados do trabalho docente sem considerar tal processo ao longo de anos. Os resultados alcançados por um professor podem não se evidenciar rapidamente; por vezes, o que aluno aprende só é usado ou testado muitos anos após ter sido ensinado (DOLTON; MCINTOSH; CHEVALIER, 2003). Ao discutirem a questão do pagamento e do desempenho do professor na Inglaterra, estes autores chamam a atenção para a complexidade de se avaliar o trabalho docente, principalmente, quando vinculado à definição da sua remuneração.

\section{Composição da remuneração}

A composição remuneratória do magistério compreende o VB do cargo mais vantagens e benefícios fixos ou variáveis. Desde a instituição da carreira (1975), verifica-se que a remuneração está referida a tabelas de vencimentos e os valores de algumas vantagens estão nelas baseados.

Até 1974, o professor recebia vencimento sem direito a vantagens adicionais, que começaram a ser instituídas a partir de então, tal como evidenciado na Tabela 5. Com o Estatuto de 1992, foi assegurado pela primeira vez um piso salarial profissional, com database e garantia de que não seria menor do que a média dos valores reais do padrão inicial de vencimento do último ano.

Em essência, a remuneração docente tem sido determinada pelo tempo de serviço e qualificação, variáveis que agregam vantagens fixas aos salários. Apesar disso, varia do ponto de vista individual, pela concessão de benefícios transitórios, 
tais como gratificações, adicionais, auxílios, abonos e prêmios, conforme mostra o Quadro 3, a seguir.

\section{Quadro 3}

Histórico das vantagens componentes da remuneração docente

\begin{tabular}{|c|c|c|}
\hline Vantagem & Duração & Descrição \\
\hline Sexta parte & $1974-$ hoje & $\begin{array}{l}\text { Adicional por tempo de serviço: } 1 / 6 \text { do Padrão de Vencimento } \\
\text { (PV), após } 25 \text { anos de efetivo exercício ( } 20 \text { anos, desde 1990) }\end{array}$ \\
\hline $\begin{array}{l}\text { Gratificação de } \\
\text { nível }\end{array}$ & $1975-1981$ & $\begin{array}{l}\text { Licenciatura curta adicional de } 46 \% \text { sobre PV inicial e } \\
\text { licenciatura plena de } 61 \% \text {. Estendida a docentes Nível II (1977) } \\
\text { e não efetivos (1978) }\end{array}$ \\
\hline $\begin{array}{l}\text { Gratificação de } \\
\text { Natal }\end{array}$ & 1979 - hoje & Modificado para 13º salário (1989) \\
\hline Quinquênio & 1979 - hoje & $\begin{array}{l}\text { Adicional por tempo de serviço, calculado sobre PV: } 5 \text { a } 10 \text { anos } \\
\text { - 5\%; } 10 \text { a } 15 \text { anos - } 10,25 \% ; 15 \text { a } 20 \text { anos - } 15,76 ; 20 \text { a } 25 \text { anos - } \\
21,55 \% ; 25 \text { a } 30 \text { anos - } 27,63 \% ; 30 \text { a } 35 \text { anos - } 34,01 \% \text {; mais de } 35 \\
\text { anos - } 40,71 \% \text {. Incorporado à aposentadoria }\end{array}$ \\
\hline Vale-transporte & 1988 - hoje & $\begin{array}{l}\text { Modificado para auxílio-transporte (2001). Valor = montante que } \\
\text { ultrapassar } 6 \% \text { do PV }\end{array}$ \\
\hline Adicional noturno & 1991 - hoje & $30 \%$ sobre valor da hora-aula entre $19 \mathrm{~h}$ e $23 \mathrm{~h}$ \\
\hline $\begin{array}{l}\text { Gratificação de } \\
\text { difícil acesso }\end{array}$ & 1991 - hoje & $\begin{array}{l}\text { Entre } 30 \% \text { e } 50 \% \text { sobre o VB da classe inicial da carreira, a } \\
\text { depender do local da escola }\end{array}$ \\
\hline Auxílio-refeição & 1999 - hoje & $\begin{array}{l}\text { Valor mensal R\$270,38 (05/2012) - menos a docente em Jornada } \\
\text { Básica }\end{array}$ \\
\hline $\begin{array}{l}\text { Gratificação por } \\
\text { Desenvolvimento } \\
\text { Educacional }\end{array}$ & $2001-2008$ & $\begin{array}{l}\text { Calculada sobre desempenho da escola, paga ao final do ano. } \\
\text { Considera índice de ocupação, tempo de permanência no } \\
\text { cargos/funções, avaliação de desempenho e assiduidade. Valor } \\
\text { máximo - CEI: } 50 \% \text { da referência QPP07A }{ }^{9} \text {; Escolas: até } 100 \% \text { da } \\
\text { referência QPE14A }\end{array}$ \\
\hline Abono permanência & 2005 - hoje & $\begin{array}{l}\text { Para os que permanecem na ativa. Valor = contribuição social } \\
\text { devida à Previdência }\end{array}$ \\
\hline Abono natalino & 2005 & $\mathrm{R} \$ 300,00$ \\
\hline $\begin{array}{l}\text { Gratificação de } \\
\text { regência }\end{array}$ & $2006-2008$ & $\begin{array}{l}\text { Para docentes Classes I e II em efetivo exercício e regência. } \\
\text { Estipulado pela jornada e categoria: entre } \mathrm{R} \$ 125,00 \text {, para JB } \\
\text { Categoria } 1 \text {, e } \mathrm{R} \$ 450,00 \text {, para JEI titulares de cargo de Professor } \\
\text { de Desenvolvimento Infantil (PDI) Categoria 3, incorporado ao } \\
\text { VB }\end{array}$ \\
\hline $\begin{array}{l}\text { Gratificação de } \\
\text { atividade educativa }\end{array}$ & $2006-2008$ & $\begin{array}{l}\text { Para titulares de cargos de Auxiliar de Desenvolvimento Infantil } \\
\text { (ADI) em efetivo exercício, com valor de } \mathrm{R} \$ 93,75 \text {, incorporado } \\
\text { ao VB }\end{array}$ \\
\hline
\end{tabular}




\begin{tabular}{|l|c|l|}
\hline $\begin{array}{l}\text { Gratificação de } \\
\text { apoio educacional }\end{array}$ & $2006-2008$ & $\begin{array}{l}\text { Para docentes designados e no efetivo exercício da função de } \\
\text { auxiliar de direção, varia entre R\$ 187,50 e R\$ 337,50, de acordo } \\
\text { com categoria, incorporado ao VB }\end{array}$ \\
\hline $\begin{array}{l}\text { Gratificação } \\
\text { de atribuição } \\
\text { educacional }\end{array}$ & $2006-2008$ & $\begin{array}{l}\text { Para designados à coordenação geral, assistência à coordenação } \\
\text { e por aspectos pedagógicos e educacionais no Centro Integrado } \\
\text { de Educação de Jovens e Adultos. Valor de R\$ 400,00, } \\
\text { incorporado ao VB }\end{array}$ \\
\hline $\begin{array}{l}\text { Gratificação } \\
\text { especial para } \\
\text { especialistas }\end{array}$ & $2006-2008$ & $\begin{array}{l}\text { Para docentes Classe III em efetivo exercício. Valor R\$ 600,00, } \\
\text { incorporado ao VB }\end{array}$ \\
\hline $\begin{array}{l}\text { Gratificação por } \\
\text { desenvolvimento } \\
\text { socioeducativo }\end{array}$ & $2006-2008$ & $\begin{array}{l}\text { Para PDI e ADI em efetivo exercício nos Centros de Convivência } \\
\text { Infantil e nos Centros Integrados de Proteção à Criança. Valor } \\
\text { máximo para CEI: 50\% da referência QPP07A, incorporado ao } \\
\text { VB }\end{array}$ \\
\hline $\begin{array}{l}\text { Abono } \\
\text { complementar }\end{array}$ & $2006-$ hoje & $\begin{array}{l}\text { Para docentes Classes I e II. Limite fixado entre R\$ 700,00 e R\$ } \\
1.900,00 . \text { Apurado conforme a diferença entre o limite e a soma } \\
\text { do PV com gratificações percebidas anteriormente }\end{array}$ \\
\hline $\begin{array}{l}\text { Vale-alimentação } \\
\text { Prêmio por } \\
\begin{array}{l}\text { Desempenho } \\
\text { Educacional (PDE) }\end{array}\end{array}$ & $\begin{array}{l}\text { Em 2012: R\$ 234,03 para servidores com remuneração bruta } \\
\text { inferior a cinco salários mínimos }\end{array}$ \\
\hline
\end{tabular}

Fonte: elaboração dos autores, com base em leis e decretos municipais (1974-2008).

Observa-se que, até 1999, tinham-se as vantagens permanentes, incorporadas à aposentadoria (sexta parte, quinquênios, $13^{\circ}$ salário); vantagens relacionadas aos direitos gerais dos trabalhadores (vale-transporte, auxílio-refeição, adicional noturno); e a gratificação de nível para professores com licenciatura curta e plena, denotando uma política remuneratória baseada no VB. A partir de 2001, há incremento no número de gratificações pontuais, algumas vinculadas ao Sistema de Avaliação Institucional de Avaliação Municipal, como é o caso do PDE, indicando uma tendência a vincular parte da remuneração às novas formas de avaliar o desempenho docente. Destaca-se, também, um grande número de gratificações que foram concedidas em 2006 e incorporadas ao VB em 2008. Essa incorporação pode ser percebida no aumento do valor da hora-aula em 2008 em relação a 2006 e 2007, conforme mostra o Gráfico 1.

\section{Considerações finais}

No período estudado, houve ampliação física e do quadro de profissionais da rede municipal de São Paulo. Nesse processo, expandiram-se as tensões relativas 
às questões salariais, às condições de trabalho, às propostas pedagógicas, entre outras, envolvendo tanto a administração pública quanto a manifestação organizada de movimentos sociais e ações sindicais. Tais conflitos se expressaram nas diferentes configurações administrativo-político-institucionais e na legislação, que neste texto foi entendida como síntese da expressão de interesses e projetos em disputa e da correlação de forças em dado momento histórico. Infelizmente, como a dinâmica que envolve os fatores e os agentes em disputa não foi objeto de análise, buscou-se ao menos situar a conjuntura política paulistana, citando o nome do prefeito municipal, quando da entrada em vigor da legislação, permitindo ao leitor inferir as tensões existentes. Tal procedimento de forma alguma consagra somente aos governantes a responsabilidade pelas alterações legais.

Além disso, o trabalho alinha-se aos estudos que tratam da remuneração docente da educação básica, em que fazem parte a descrição e a análise de planos de carreira em diferentes esferas administrativas, em termos atuais e históricos. Sua contribuição refere-se ao registro descritivo e analítico das alterações legais nos aspectos tratados.

Quanto à forma de ingresso, destaca-se no município de São Paulo o concurso público, desde 1937. Houve, no período, mudanças nas denominações, criação e extinção de cargos de docentes, em vista da adequação à legislação nacional e ao atendimento escolar. Com menor presença, a rede municipal também contou com não efetivos para suprir demandas emergenciais. Em 1992, foi criado o cargo de professor adjunto para suprir ausências e licenças de professores. Com a extinção desse cargo, há hoje na rede um número maior de professores efetivos por escola com vistas à substituição em situações de faltas ou licenças. A incorporação das creches à SME (2002) deu origem ao cargo de PDI, cujo ingresso ocorre por concurso público, com a mesma previsão de enquadramento dos demais docentes, desde que o pretendente possua a formação mínima exigida. Portanto, para todos os cargos nota-se exigência progressiva de maior formação.

Quanto à jornada de trabalho, houve variação em relação à quantidade, que aumentou principalmente a partir de 1993, ao número de horas e à composição, com a criação de uma jornada com um terço do tempo para atividades extraclasse, contemplando a formação continuada, em 1992. Salienta-se, contudo, que a variação entre o tempo de trabalho extraclasse e o tempo de ensino do docente nas diferentes jornadas foi de $10 \%$ a $37,5 \%$ no período.

No que diz respeito à movimentação na carreira, há dispositivos válidos para todo o funcionalismo municipal, bem como os específicos para o magistério. Preponderam critérios de tempo de serviço e titulação para qualquer movimentação. Os conceitos que definiram as diferentes tabelas de vencimentos também 
variaram ao longo da história. A avaliação do desempenho docente esteve sempre presente, sem - até o momento - vincular-se ao desempenho dos alunos em avaliações externas.

A dispersão no vencimento sofreu variações, em geral relacionadas à superação de fortes processos inflacionários. O menor valor observado foi 1,6, em 1988, e o maior correspondeu a 3,8, em 1989. Desde 1994, tal relação manteve-se estável, em torno de 2,4. Nas tabelas de vencimentos identifica-se uma diferença de 6,5\%, em movimentação vertical ou horizontal, entre cada uma das referências e dos níveis estabelecidos.

Finalmente, quanto à composição da remuneração, nota-se que, com a instituição da carreira (1975), estabeleceu-se o recebimento de vantagens e benefícios

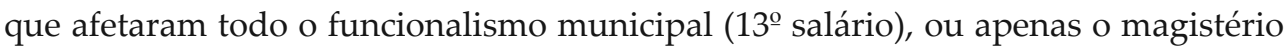
(gratificação de difícil acesso); com valores padronizados (13ํㅜ salário), ou referidos à tabela de vencimentos (prêmio por desempenho educacional); fixos, computados na composição remuneratória mesmo na aposentadoria (quinquênios, sexta parte), ou variáveis/transitórios, ausentes quando da mudança de unidade sede, lotação do docente ou aposentadoria (gratificação de difícil acesso, adicional noturno).

Na rede municipal de São Paulo, bem como em outras redes públicas, há uma série de adicionais, gratificações, auxílios, abonos e prêmios que compõem com os vencimentos a remuneração docente. Seu estudo de forma sistemática poderá melhor identificar as tensões entre os docentes e as administrações públicas, apontando alternativas para a construção de carreiras condignas à realização de uma educação de qualidade. Certamente, tarefa para outros estudos.

\section{Notas}

1. Segundo o IBGE, a rede municipal contava com 1.958 docentes, em 1966 (http://www.ibge.gov.br/ seculoxx/) e, em 2010, com 56.872, uma expansão de $2.900 \%$.

2. O IGP-DI, calculado pela Fundação Getúlio Vargas desde fevereiro de 1944, foi selecionado, pois cobre a série histórica e tem como finalidade medir o comportamento dos preços em geral da economia brasileira.

3. Dispersão do vencimento refere-se à diferença percentual entre vencimento inicial e final da carreira.

4. A movimentação na carreira ocorre de forma vertical, referências (11 a 21), e horizontal, graus (A a E), conforme Tabela 1 .

5. Até 2012, o tempo da hora-aula e da hora-atividade na rede municipal correspondia a 45 minutos. Dessa forma, 40 horas-aula da JEI correspondiam a 30 horas da JTI.

6. A Lei n. 14.660/07 acabou com o cargo de professor adjunto e criou o conceito de "módulo", que se refere aos docentes concursados que permanecem na escola para substituir colegas em caso de licença, faltas etc.

7. Dados fornecidos pela SME em 2010, de acordo com a declaração de acúmulo de cargo dos docentes, obrigatória somente para acúmulo em redes públicas. 
8. A sigla EM (Ensino Municipal) acompanhada de um número diz respeito à referência em que o professor se encontra, conforme Tabela 2.

9. QPP designa o Quadro dos Profissionais da Promoção Social da Prefeitura de São Paulo.

\section{Referências}

ABREU, M.V.; BALZANO, S. Progressão na carreira do magistério e avaliação de desempenho. In: RODRIGUES, M.M.; GIÁGIO, M. (Org.). Guia de consulta para o Programa de Apoio aos Secretários Municipais de Educação - Prasem III. Brasília, DF: Fundescola/ MEC, 2001.

BRASIL. Constituição (1934). Constituição da República dos Estados Unidos do Brasil. 1934.

BRASIL. Constituição (1988). Constituição da República Federativa do Brasil. Brasília, DF: Senado, 1988.

BRASIL. Emenda Constitucional n. 14, 12 dez. 1996.

BRASIL. Emenda Constitucional n. 19, 4 jun. 1998.

BRASIL. Lei n. 4.024, 20 dez. 1961.

BRASIL. Lei n. 5.692, 11 ago. 1971.

BRASIL. Lei n. 9.394, 20 dez. 1996.

BRASIL. Lei n. 9.424, 24 dez. 1996.

BRASIL. Lei n. 11.738, 16 jul. 2008.

BRASIL. Parecer CNE/CEB n. 9/2009, 2 abr. 2009. Brasília, DF: MEC, 2009.

BRASIL. Resolução CNE/CEB n. 2, 28 maio 2009.Brasília, DF: MEC, 2009.

CAMARGO, R.B. Gestão democrática e nova qualidade de ensino: o conselho de escola e o projeto da interdisciplinaridade nas escolas municipais da cidade de São Paulo (1989-1992). 1997. Tese (Doutorado em Educação) - Faculdade de Educação, Universidade de São Paulo, São Paulo.

DOLTON, P.; MCINTOSH, S.; CHEVALIER, A. Teacher pay and performance. London: Institute of Education, University of London, 2003.

DUTRA JUNIOR, A. et al. Plano de carreira e remuneração do magistério público: LDB, Fundef, diretrizes nacionais e nova concepção de carreira. Brasília, DF: Fundescola/ MEC, 2000. 
FANFANI, E.T. Consideraciones sociologicas sobre profesionalización docente. Educação \& Sociedade, Campinas, v. 28, n. 99, p. 335-353, maio/ago. 2007.

GATTI, B.A.; BARRETO, E.S. Professores do Brasil: impasses e desafios. Brasília, DF: Unesco, 2009.

GATTI, B. A. et al. Atratividade da carreira docente no Brasil. São Paulo: FCC, 2009. (Relatório preliminar).

MATOS, A.R. Trajetória do Sindicato dos Profissionais em Educação no Ensino Municipal (SINPEEM): 1986-2004. 2010. Dissertação (Mestrado em Educação) - Centro Universitário Nove de Julho (Uninove), São Paulo.

MONLEVADE, J.A. Valorização salarial dos professores: o papel do Piso Salarial Profissional Nacional como instrumento de valorização dos professores da educação básica pública. 2000. Tese (Doutorado em Educação) - Programa de Pós-Graduação em Educação, Faculdade de Educação, Universidade Estadual de Campinas, Campinas.

MORDUCHOWICZ, A. Carreiras, incentivos e estruturas salariais docentes. Rio de Janeiro: Preal Brasil, 2003.

OLIVEIRA, D.A. A reestruturação do trabalho docente: precarização e flexibilização. Educação \& Sociedade, Campinas, v. 25, n. 89, p. 1127-1144, set./dez. 2004.

OLIVEIRA, D.A. Regulação educativa na América Latina: repercussões sobre a identidade dos trabalhadores docentes. Educação em Revista, Belo Horizonte, v. 44, p. 209-227, dez. 2006.

SÃO PAULO. Ato n. 767, 9 jan. 1935.

SÃO PAULO. Decreto n. 3.185, 28 maio 1956.

SÃO PAULO. Decreto n. 22.366, 26 jun. 1986.

SÃO PAULO. Decreto n. 33.792, 3 nov. 1993.

SÃO PAULO. Decreto n. 51.526, 29 maio 2010.

SÃO PAULO. Decreto-lei n. 360, 13 ago. 1946.

SÃO PAULO. Lei n. 5.607, 3 jun. 1959.

SÃO PAULO. Lei n. 7.037, 13 jun. 1967.

SÃO PAULO. Lei $n^{\circ}$ 7.693, 6 jan. 1972.

SÃO PAULO. Lei n. 8.183, 20 dez. 1974.

SÃO PAULO. Lei n. 8.209, 4 mar. 1975. 
SÃO PAULO. Lei n. 8.519, 3 jan. 1977.

SÃO PAULO. Lei n. 8.694,31 mar. 1978.

SÃO PAULO. Lei n. 8.807, 26 out. 1978.

SÃO PAULO. Lei n. 8.989, 29 out. 1979.

SÃO PAULO. Lei n. 9.662, 28 dez. 1983.

SÃO PAULO. Lei n. 9.874, 18 jan. 1985.

SÃO PAULO. Lei n. 10.779, 5 dez. 1989.

SÃO PAULO. Lei n. 11.229, 26 jun. 1992.

SÃO PAULO. Lei n. 11.434, 12 nov. 1993.

SÃO PAULO. Lei n. 13.695, 19 dez. 2003.

SÃO PAULO. Lei n. 13.748, 16 jan. 2004.

SÃO PAULO. Lei n. 14.660, 26 dez. 2007.

SÃO PAULO. Prefeitura Municipal. Lei n. 4.128, de 20 nov. 1951.

TEDESCO, J.C.; FANFANI, E.T. Nuevos maestros para nuevos estudiantes. In: PEARLMAN, M. et al. Maestros en América Latina: nuevas perspectivas sobre su formación y desempeño. Chile: San Marino; Preal; BID, 2004.

VEGAS, E.; UMANSKY, I. Mejorar la enseñanza y el aprendizaje por medio de incentivos. Qué lecciones nos entregan las reformas educativas de América Latina? Washington, DC: Banco Mundial, 2005.

Recebido em 30 de julho de 2012.

Aprovado em 25 de outubro de 2013. 